\title{
Inventário da arborização urbana e descrição das características físicas das principais vias do setor central de Gurupi (TO)
}

\author{
Urban arborization inventory and description of the physical characteristics of \\ the main streets in the central area of Gurupi (TO)
}

\author{
Lucicléia Mendes de Oliveira ${ }^{1}$ \\ André Ferreira dos Santos ${ }^{2}$ \\ Patrícia Aparecida de Souza ${ }^{3}$ \\ Marcos Giongo $\left.{ }^{4}{ }^{*}\right)$
}

\section{Resumo}

\begin{abstract}
Arborização urbana é um assunto que vem ganhando expressão atualmente por melhorar o aspecto estético do meio urbano, reduzir a poluição, trazer conforto térmico, especialmente em locais cujas temperaturas são elevadas. No entanto, é necessário fazer um planejamento adequado para haver a convivência harmônica entre vegetação e estrutura física urbana. O objetivo do trabalho foi realizar o inventário da arborização nas principais vias do setor central de Gurupi, Tocantins e diagnosticar os problemas decorrentes da arborização sem planejamento. O levantamento de dados em campo foi realizado de fevereiro a maio de 2014, utilizando como método o inventário do tipo censo, no qual foram levantadas as seguintes características das espécies arbóreas: altura total, altura da primeira bifurcação, circunferência a altura do peito, presença de injúrias, problemas com fiação elétrica, necessidade e intensidade de realização de podas ou não; e também as características das avenidas e ruas: largura de calçada, com ou sem pavimentação, danos causados às calçadas. Foram encontrados 1.942 indivíduos arbóreos, os quais são distribuídos entre 18 famílias e 52 espécies, sendo que 27 são exóticas e 25 nativas. A arborização analisada apresenta caráter pouco heterogêneo onde há predominância de Licania tomentosa (Benth). Fritsch e os indivíduos adultos em sua maioria $(92,3 \%)$, estão localizados em calçadas pavimentadas, sendo, desses total, verificado que as raízes de 47,3\% das árvores causavam algum tipo de dano. O uso de
\end{abstract}

1 Dra.; Ciência e Tecnologia de Sementes; Universidade Federal de Pelotas, UFPEL, Brasil; Atua nos seguintes temas: qualidade fisiológica de sementes de grandes culturas e espécies florestais, arborização urbana e fitossociologia; E-Mail: lucicleia@biologa.bio.br

2 Dr.; Agronomia; Universidade Estadual Paulista Júlio de Mesquita Filho, UNESP, Brasil; Professor Adjunto do curso de Engenharia Florestal e de Agronomia e Professor do curso de Mestrado em Ciências Florestais e Ambiental da Universidade Federal do Tocantins - Campus Gurupi-TO; Endereço: Universidade Federal do Tocantins, Campus Universitário de Gurupi. Rua Badejós, Chacaras 69/72, Lote 7, Zona Rural. CEP: 77420970 - Gurupi, TO - Brasil; E-Mail: andrefs@uft.edu.br

3 Dra.; Ciência Florestal; Universidade Federal de Viçosa, UFV, Brasil; Professor assistente da Universidade Federal de São João Del Rei; Endereço: Universidade Federal de São João Del-Rei. Rua Sétimo Moreira Martins, 188, Bairro Itapuã. CEP: 77402970 - Sete Lagoas, MG - Brasil; E-Mail: patriciaapsouza@uft.edu.br

4 Dr.; Ambiente e Territorio; Università degli Studi del Molise, UNIMOL, Itália; professor da Universidade Federal do Tocantins (UFT) e Coordenador do Centro de Monitoramento Ambiental e Manejo do Fogo (CeMAF); Endereço : Universidade Federal do Tocantins, Campus Universitário de Gurupi, Centro de Monitoramento Ambiental e Manejo do Fogo (CeMAF). Rua Badejós, Chácaras 69 e 72, Lt. 07, Sevilha. 77402970 - Gurupi, TO - Brasil E-Mail: giongo@ uft.edu.br $\left(^{*}\right)$ Autor para correspondências

\begin{tabular}{llllll}
\hline Ambiência & Guarapuava (PR) & v.14 n.3 & p.477-495 & Set/Dez 2018 & ISSN $1808-0251$
\end{tabular}


mudas de plantas mal conduzidas é um problema gravíssimo constatado pela altura da primeira bifurcação, bem como através do diâmetro à altura do peito, nas árvores adultas, o que reflete diretamente nos custos de manutenção com podas.

Palavras chave: vegetação; calçadas verdes; planejamento.

\section{Abstract}

Urban forestry is a subject that has been gaining significance recently regarding that it improves the aesthetic appearance of the urban environment, decreases air pollution, and brings thermal comfort, especially in places with high temperatures. It requires proper planning in order to obtain harmonic coexistence between vegetation and urban physical structure. In this context, the study aimed to carry out an urban vegetation inventory on the main streets of Gurupi's central area, and also to identify problems resulting from absence of planning. Field data survey was conducted from February to May 2014, using the method of inventory type census, which measured the following characteristics of tree species: total height, height of the first fork formation, circumference at breast height, presence of injuries, problems with power lines, necessity and intensity of conducting pruning or not; as well as characteristics of the streets: sidewalk width, with or without paving, damage to sidewalks. 1,942 individual trees were found, which are distributed among 18 families and 52 species, 27 being exotic and 25 native. Following conclusions were made: Gurupi's urban forestry has little heterogeneity where there is predominance of Licania tomentosa (Benth.) Fritsch, and adult individuals (92.3\%) are located on paved sidewalks, of which $47.3 \%$ of the roots were found to cause some type of damage. The use of seedlings of poorly managed plants is a very serious problem verified by the height of the first bifurcation, as well as through the diameter of the chest height in adult trees, which directly reflects pruning maintenance costs.

Key words: vegetation; green sidewalks; planning.

\section{Introdução}

O inventário florestal se mostra importante pois viabiliza a obtenção de dados quantitativos e qualitativos de uma determinada área ou região para fornecer informações sobre o planejamento, bem como o manejo de florestas visando à sua conservação e também medidas corretivas (VIBRANS et al., 2012). Quando se trata do manejo dos indivíduos arbóreos de uma cidade, o inventário se mostra essencial, pois, através dele, é possível conhecer o patrimônio arbóreo e identificar as necessidades de manejo, principalmente se o inventário for realizado de maneira continua, fornecendo sempre dados atualizados. Possibilita, ainda, que os responsáveis pelo planejamento e manutenção da arborização urbana tornem-se mais hábeis em reduzir os custos de manutenção, bem como, lançar estratégias de intervenção para o replanejamento de forma mais adequada (SILVA et al., 2007).

A arborização urbana é implementada em diversas cidades brasileiras e, muitas vezes, sem um planejamento prévio, o qual em vez de trazer benefícios acarreta uma série de transtornos, pois segundo Santos et al. (2013), ocorre a utilização de espécies de porte inadequado que podem causar prejuízos, como: a interferência das árvores na fiação elétrica, nas placas de sinalização e 
nas edificações; sujam as ruas e as avenidas; dificultam o acesso dos pedestres, por ocuparem as calçadas, consequentemente, colocando-os em situação de risco (MONTEIRO et al., 2013). Sendo também responsável pela baixa diversidade de espécies em várias cidades, devido à inexistência do levantamento das espécies que ocorrem no local. Levando à utilização de espécies inadequadas para o espaço disponível, além das condições inadequadas para o seu desenvolvimento como: o tamanho reduzido das covas, área livre reduzida ou ausente, ausência de tutoramento, a constância de podas emergenciais, em geral, mal executadas e a ausência de podas de formação e limpeza (ARAÚJO et al., 2009; RABER; REBELATO, 2010).

Segundo Osako et al. (2016), apesar de a arborização urbana não ser tratada como um tema de grande importância no país, tendo em vista que a educação ambiental é pouco difundida pelos sistemas de ensino, o poder público é responsável por isso, já que, nas secretárias urbanísticas e ambiental, existem pessoas sem capacitação técnica e teórica sobre o tema. Sendo assim, políticas públicas devem incentivar sobre a implementação de planos de arborização urbana para melhorar a infraestrutura urbana e, simultaneamente, usufruir dos benefícios proporcionados pela vegetação como os ecológicos, os estéticos e os psicológicos.

Os benefícios ecológicos da arborização estão relacionados ao microclima, que favorece a menor amplitude térmica, maior umidade relativa, menor velocidade do vento e menor velocidade da precipitação pluviométrica; exerce papel sobre a fauna, através do fornecimento de flores e abrigos para os animais; controle da erosão eólica e hídrica do solo; manutenção da qualidade e quantidade de água; retém poeiras e sólidos em suspensão e amenização da poluição sonora (MONTEIRO et al., 2013).

A vegetação melhora o aspecto estético da cidade, contribuindo através de suas qualidades plásticas (cor, forma e textura) na moldura de ruas, avenidas e, reduzindo o efeito agressivo das construções que dominam a paisagem urbana devido à sua capacidade de integrar os vários componentes do sistema. Outro aspecto é o psicológico que, embora seja difícil de quantificar, é expresso através da satisfação que as pessoas sentem ao está em contato com a vegetação e com ambiente criado pelas plantas (DANTAS; SOUZA, 2004).

Para se obter os benefícios ambientais e paisagísticos da arborização urbana, é necessário uma ação continua e integrada entre a prefeitura e a população, o que muitas vezes só é possível pelo estabelecimento de políticas ambientais envolvendo ações de educação ambiental. Estas orientam a comunidade, enfatizam a importância da arborização e incentivam o plantio e o cuidado com as árvores. Isto ocorre através do monitoramento sistemático, podas realizadas no momento adequado, remoção, substituição, plantio e combate das pragas e doenças (PIRES et al., 2010).

Também é essencial o uso correto das espécies arbóreas, uma vez que o uso indevido poderá acarretar prejuízos tanto para o usuário quanto para as empresas prestadoras de serviços de rede elétrica, telefônica e saneamento básico (DANTAS; SOUZA, 2004). Portanto, a realização de um inventário de arborização urbana é importante devido à possibilidade de direcionar a tomada de decisões para o planejamento da arborização das cidades, sendo indispensável o levantamento de informações relacionadas à espécie, porte, altura da primeira bifurcação, espaçamento entre árvores, distância em relação à construção, espaço para seu desenvolvimento, entre outros fatores. Pois contata-se que a maioria das cidades brasileiras não tem planejamento nem programas de manutenção adequados para evitar problemas atuais e futuros.

Diante do exposto, a pesquisa teve por objetivo realizar o inventário quali-quantitativo da arborização de acompanhamento viário e descrever as características físicas das vias estudadas 
no setor central de Gurupi, Tocantins, para discutir os problemas encontrados nessa cidade, em virtude da ausência de planejamento de arborização e, de posse dessas informações, subsidiar a elaboração de futuros projetos.

\section{Material e Métodos}

\section{Área de estudo}

A área de estudo localiza-se no setor central da sede municipal de Gurupi, localizado na região sul do estado do Tocantins, com latitude de 11\%43'45" sul e longitude de 4904'07" oeste e altitude de 287 metros. Faz limites com as cidades Aliança do Tocantins, Cariri do Tocantins, Dueré, Figueirópolis, Peixe e Sucupira, e cerca de $245 \mathrm{~km}$ distante da capital, Palmas (SEPLAN, 2012). O clima, segundo a classificação de Thornthwaite, é do tipo C2wA'a" úmido subúmido com moderada deficiência hídrica (SEPLAN, 2013). Sua população, estimada em 2017, era de 85.523 habitantes com densidade demográfica 46,58 hab. $\mathrm{km}^{-2}$ e área territorial $1.836,081 \mathrm{~km}^{2}$ (IBGE, 2018).

Para a localização das vias e ruas da área de estudo foi utilizado como base o mapa viário da cidade no qual constaram os nomes das vias. A área total (Figura 1) amostrada totaliza 13 avenidas e 10 ruas, tomando como unidade amostral a quadra, das quais foram inventariadas 108 , com exceção das áreas verdes e propriedades particulares.

\section{Figura 1 - Mapa de localização da área de estudo, na qual foi realizado o inventário da arborização urbana do setor central da sede municipal de Gurupi (TO).}
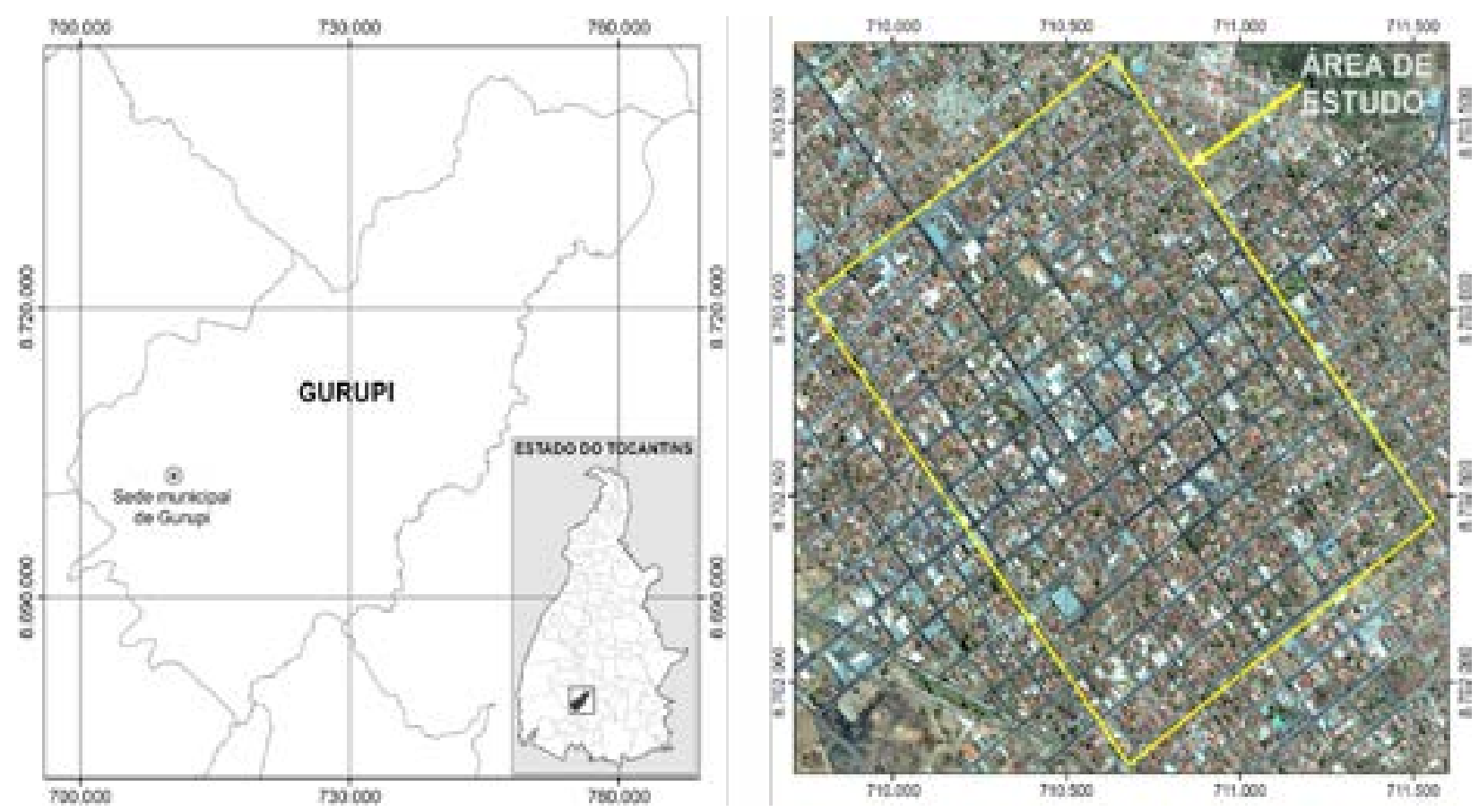

Fonte: Autores (2015). 


\section{Coleta e avaliação dos dados}

Foi realizado um inventário do tipo censo, em que todos os indivíduos arbóreos presentes na área de estudo foram identificados e contabilizados, sendo identificadas inicialmente através de nome popular durante a coleta e, no caso de dúvidas, foram coletadas amostras botânicas para serem comparadas com bibliografias especializadas e, também, consulta ao herbário da Universidade Federal do Tocantins (UFT), em Porto Nacional, Tocantins.

A coleta de dados em campo foi realizada durante os meses de fevereiro a maio de 2014, no qual foram levantadas as informações das espécies arbóreas: altura total, altura da primeira bifurcação, circunferência à altura do peito (CAP), presença de injúrias, problemas com fiação elétrica, necessidade e intensidade de realização de podas ou não; e das avenidas e ruas: largura de calçada, com ou sem pavimentação, danos causados às calçadas, conforme descrito a seguir e especificadas as categorias no quadro 1:

Para árvores: Altura total - a medição foi realizada com auxílio do equipamento clinômetro haglöf. Os indivíduos foram agrupados quanto à fase de desenvolvimento sendo consideradas mudas aquelas com altura inferior a 1,50 $\mathrm{m}$ e as árvores em: pequeno (até $6 \mathrm{~m}$ ), médio (6 a $12 \mathrm{~m}$ ) e grande (acima de $12 \mathrm{~m}$ ) porte baseando-se em Porto e Silva (2013) com adaptações; Altura da primeira bifurcação - aferida utilizando trena, sendo posteriormente separados em dois grupos: um com altura inferior e o outro superior a 1,80 m (PORTO e SILVA, 2013); Circunferência a altura do peito - medida a partir de $1,30 \mathrm{~m}$ de altura do tronco, quando não havia ramificação, no entanto, indivíduos com valores inferiores a esse não foram contemplados, posteriormente os valores de circunferências foram convertidos em diê; Presença de injúrias - classificadas de acordo com sua localização nas partes da árvore (caule ou raiz), e em caso de não verificação de nenhuma injúria aparente foram incluídas na categoria sem injúrias, sendo agrupadas em cinco categorias, tabela 1 (método baseado em EMER et al. 2013); Conflitos com a fiação elétrica - avaliado se havia conflito com as árvores, sendo agrupados em quatro categorias (quadro 1) segundo Melo et al. (2007); Necessidade de poda - agrupado em seis categorias (tabela 1) e Intensidade de poda - agrupados em quatro categorias, quadro 1 (método baseado em BATISTEL et al., 2009; SILVA et al. 2012).

Para avenidas e ruas: Largura de calçada - Medida com o auxílio de trena de $30 \mathrm{~m}$; Pavimentação - Foram adotadas duas classes, com e sem pavimento. E quando pavimentada foram observados os problemas provocados pelas raízes em relação às calçadas; Danos causados às calçadas - os tipos de danos foram agrupados em três categorias conforme Melo et al. (2007). 


\section{Tabela 1- Detalhamento das categorias das variáveis analisadas:}

\begin{tabular}{ll}
\hline \multicolumn{1}{c}{ Variáveis } & \multicolumn{1}{c}{ Categorias } \\
\hline Presença de injúrias & 1-ausência de injúria; 2-dano por poda; 3-vandalismo; 4- doença/praga. \\
Conflitos com a fiação elétrica & 1-Ausente; 2-abaixo da copa; 3-atravessa a copa e 4-acima da copa. \\
Necessidade de poda & 1-nenhuma; 2-afastamento da construção; 3-liberação de rede; \\
& 4-levantamento de copa; 5-condução e 6-abaixar copa. \\
Intensidade de poda & 1-nenhuma; 2-leve; 3-pesada e 4-drástica. \\
Pavimentação & 0-sem; 1-com. \\
Danos causados às calçadas & 1-nenhum; 2-aponta/trinca e 3-quebra. \\
\hline
\end{tabular}

A classificação das famílias botânicas seguiu a classificação APG (APG III, 2009). Foram identificadas as plantas, constando família, nome científico, quantidade, classificação quanto à origem em nativas e exóticas. Para este trabalho foram consideradas apenas as árvores, sendo listada a quantidade total de espécies identificadas; em seguida, foram agrupadas em duas fases de desenvolvimento, adultas e mudas e, posteriormente, apenas as adultas foram consideradas para o diagnóstico da arborização.

Para a identificação e classificação das espécies quanto a sua origem (exótica/nativa), foram classificadas como nativas aquelas pertencentes à flora brasileira, bem como as nativas do Bioma Cerrado, sendo, para isso, consultadas bibliografias especializadas (CORREIA, 1984; LORENZI, 998a; LORENZI, 1998b; LORENZI et al., 2003; CARVALHO, 2003; CARVALHO 2006; CARVALHO, 2008).

Após coleta de todos os dados do inventário, estes foram transcritos para uma planilha eletrônica utilizando o sistema computacional OpenOffice. Para determinar a abundância dos indivíduos registrados, foram calculadas as porcentagens por espécie e família em relação ao total de indivíduos amostrados, bem como a abundância de espécies nativas e exóticas, sendo também calculadas as demais determinações pela razão entre o número de indivíduos amostrados em relação ao total.

\section{Resultados e Discussão}

No inventário, foram encontradas 52 espécies vegetais e 18 famílias em um total de 1942 indivíduos (Tabela 2), classificadas como exóticas 27 espécies com 290 indivíduos (14,93\%) e 25 nativas com 652 (85,07\%). Pelos resultados encontrados, podemos constatar que a maioria dos indivíduos é de origem nativa, o que é considerado tecnicamente recomendável, segundo Paiva et al. (2010), sob o ponto de vista ecológico, adaptativo e funcional, especialmente para garantir as relações ecológicas co-evolutivas, genéticas e dispersão de propágulos envolvendo a fauna e a flora dentro do ambiente urbano, bem como a conservação do material genético.

Apesar de haver maior número de indivíduos arbóreos nativos é notória a má distribuição por espécies, comprovada pela dominância de Licania tomentosa (Benth). Fritsch que contempla $70,88 \%$ da comunidade (Tabela 2). Esse dado demonstra que a arborização de Gurupi não teve critério adequado quanto à escolha das espécies para o plantio na área urbana, refletindo na baixa diversidade de espécies no local. A abundância dessa espécie em Gurupi é explicado, devido à árvore apresentar: copa frondosa sem perda da folhagem mesmo no período seco, fornecendo sombra o ano inteiro; raízes não agressivas e por tolerar podas frequentes, e devido a um evidente desconhecimento por parte da população e dos órgãos públicos acerca da riqueza de espécies nativas da flora brasileira, especialmente as do bioma Cerrado e também devido à alta frequência 
de distribuição de mudas pela prefeitura (SANTOS et al., 2013), o mesmo foi verificado em Goiandira, Goiás por Pires et al. (2010).

\section{Tabela 2 - Relação de espécies encontradas na arborização da área de estudo em Gurupi/TO, Brasil segundo a família, espécie, nome popular, número total indivíduos $(\mathrm{N})$, abundância relativa $(A \%)$ e origem $(0)$ em nativas- $N$ e exóticas- $E$.}

\begin{tabular}{|c|c|c|c|c|c|}
\hline Família & Nome científico & Nome popular & $\mathbf{N}$ & $\mathrm{A}(\%)$ & $\mathrm{O}$ \\
\hline \multirow[t]{4}{*}{ Anacardiaceae } & Anacardium occidentale L.* & Caju & 6 & 0,31 & $\mathrm{~N}$ \\
\hline & Mangifera indica L.* & Mangueira & 41 & 2,11 & $\mathrm{E}$ \\
\hline & Schinus molle L. & Aroeira salsa & 12 & 0,62 & $\mathrm{~N}$ \\
\hline & Spondias mombin L.* & Cajá & 4 & 0,21 & $\mathrm{~N}$ \\
\hline Annonaceae & Annona squamosa L.* & Fruta do conde & 6 & 0,31 & $\mathrm{~N}$ \\
\hline \multirow[t]{2}{*}{ Apocynaceae } & Aspidosperma tomentosum Mart. & Piquiá & 1 & 0,05 & $\mathrm{~N}$ \\
\hline & Thevetia peruviana (Pers.) Schum. & $\begin{array}{l}\text { Chapéu de } \\
\text { Napoleão }\end{array}$ & 5 & 0,26 & $\mathrm{~N}$ \\
\hline \multirow[t]{6}{*}{ Bignoniaceae } & Crescentia cujete L. & Coité & 4 & 0,31 & $\mathrm{~N}$ \\
\hline & Jacaranda brasiliana (Lam.) & Caroba & 3 & 0,15 & $\mathrm{~N}$ \\
\hline & Tabebuia alba (Rild.) Sand. & Ipê amarelo & 22 & 1,13 & $\mathrm{~N}$ \\
\hline & Tabebuia aurea (Manso) Benth. \& hook & Craíba & 1 & 0,05 & $\mathrm{~N}$ \\
\hline & $\begin{array}{l}\text { Tabebuia impetiginosa (Mart. ex DC.) } \\
\text { Standl. }\end{array}$ & Ipê roxo & 5 & 0,26 & $\mathrm{~N}$ \\
\hline & Tecoma stans (L.) Juss. ex Kunth & Ipê mirim & 3 & 0,15 & $\mathrm{E}$ \\
\hline Caricaceae & Carica papaya L.* & Mamão & 2 & 0,1 & $\mathrm{E}$ \\
\hline Chrysobalanaceae & Licania tomentosa (Benth.) Fritsch & Oiti & 1378 & 70,88 & $\mathrm{~N}$ \\
\hline Combretaceae & Terminalia catappa L. & Castanhola & 18 & 0,93 & $\mathrm{E}$ \\
\hline Ebenaceae & Diospyros kaki L.f.* & Caqui & 1 & 0,05 & $\mathrm{E}$ \\
\hline \multirow[t]{10}{*}{ Fabaceae } & Adenanthera pavonina Linnaeus & Tento Carolina & 1 & 0,05 & $\mathrm{E}$ \\
\hline & Andira vermifuga Mart. ex Benth. & Angelim & 4 & 0,21 & $\mathrm{~N}$ \\
\hline & Baubinia variegata (L.) Benth & Pata de vaca & 9 & 0,46 & $\mathrm{E}$ \\
\hline & Caesalpinia pluviosa DC. & Sibipiruna & 95 & 4,89 & $\mathrm{~N}$ \\
\hline & Caesalpinia pulcherrima (L.) Sw. & Flamboyant mirim & 8 & 0,41 & $\mathrm{E}$ \\
\hline & Cassia fistula L. & Cássia imperial & 23 & 1,18 & $\mathrm{E}$ \\
\hline & Delonix regia (Boj. ex Hook.) Raf. & Flamboyant & 2 & 0,1 & $\mathrm{E}$ \\
\hline & Erythrina indica Lam. & Brasileirinho & 2 & 0,1 & $\mathrm{E}$ \\
\hline & Inga vera $\mathrm{W}$ illd. & Ingá & 2 & 0,1 & $\mathrm{~N}$ \\
\hline & Leucaena sp. & Leucena & 1 & 0,05 & $\mathrm{E}$ \\
\hline \multirow[t]{2}{*}{ Fabaceae } & Mimosa caesalpiniaefolia Benth. & Sansão do campo & 1 & 0,05 & $\mathrm{~N}$ \\
\hline & Schizolobium parahyba (Vell.) S.F. Blake & Paricá & 1 & 0,05 & $\mathrm{~N}$ \\
\hline Lamiaceae & Tectona grandis L.F. & Teca & 2 & 0,1 & $\mathrm{E}$ \\
\hline \multirow{3}{*}{$\begin{array}{c}\text { Malpighiaceae } \\
\text { Malvaceae }\end{array}$} & Malpighia glabra L.* & Acerola & 3 & 0,15 & $\mathrm{E}$ \\
\hline & Pachira aquatica Aubl. & Munguba & 87 & 4,48 & $\mathrm{~N}$ \\
\hline & Sterculia chica A. St. Hil. & Chichá & 1 & 0,05 & $\mathrm{~N}$ \\
\hline
\end{tabular}

(Continua...) 


\section{Tabela 2 - Relação de espécies encontradas na arborização da área de estudo em Gurupi/TO, Brasil segundo a família, espécie, nome popular, número total indivíduos $(\mathrm{N})$, abundância relativa $(A \%)$ e origem $(0)$ em nativas- $N$ e exóticas- $E$.}

\begin{tabular}{|c|c|c|c|c|c|}
\hline Família & Nome científico & Nome popular & $\mathbf{N}$ & $A(\%)$ & $\mathbf{O}$ \\
\hline \multirow[t]{2}{*}{ Meliaceae } & Azadirachta indica A. Juss. & Nim & 9 & 0,46 & $\mathrm{E}$ \\
\hline & Cedrela fissilis Vell. & Cedro Rosa & 1 & 0,05 & $\mathrm{~N}$ \\
\hline \multirow[t]{4}{*}{ Moraceae } & Artocarpus heterophyllus Lam.* & Jaqueira & 1 & 0,05 & $\mathrm{E}$ \\
\hline & Ficus benjamina L. & Fícus & 25 & 1,29 & $E$ \\
\hline & Ficus mexiae Standl. & Figueira preta & 3 & 0,15 & $\mathrm{~N}$ \\
\hline & Morus nigra L.* & Amora & 3 & 0,15 & $\mathrm{E}$ \\
\hline \multirow[t]{5}{*}{ Myrtaceae } & Eucalyptus sp. & Eucalipto & 1 & 0,05 & $\mathrm{E}$ \\
\hline & Psidium guajava L.* & Goiabeira & 7 & 0,36 & $\mathrm{~N}$ \\
\hline & Syzygium cumini (L) Skeels* & Jambolão & 3 & 0,15 & $E$ \\
\hline & Syzygium jambos L.(Alston)* & Jambo do campo & 1 & 0,05 & $\mathrm{E}$ \\
\hline & Syzygium malaccense (L.) Merr. \& LMPerry & Jambo roxo & 39 & 2,01 & $\mathrm{E}$ \\
\hline \multirow[t]{4}{*}{ Rutaceae } & Carolus linnaeus (L.) - Burm.f* & Limão & 1 & 0,05 & $\mathrm{E}$ \\
\hline & Citrus reticulata Blanco* & Lima & 1 & 0,05 & $\mathrm{E}$ \\
\hline & Citrus sinensis $(\mathrm{L})$ osbeck* & Laranja & 1 & 0,05 & $\mathrm{E}$ \\
\hline & Murraya paniculata (L.) Jack & Jasmim Laranjeira & 83 & 4,27 & $\mathrm{E}$ \\
\hline \multirow[t]{3}{*}{ Sapindaceae } & Litchi chinensis Sonn. & Lixia & 6 & 0,31 & $\mathrm{E}$ \\
\hline & Magonia pubescens A.St.-Hil & Tingui & 1 & 0,05 & $\mathrm{~N}$ \\
\hline & Talisia esculenta (A. St.-Hil.) Radlk* & Pitomba & 1 & 0,05 & $\mathrm{~N}$ \\
\hline Tiliaceae & Apeiba tibourbou Aubl. & Pente de macaco & 1 & 0,05 & $\mathrm{~N}$ \\
\hline TOTAL $=18$ & 52 & & 1942 & 100 & - \\
\hline
\end{tabular}

*Frutiferas

Fonte: Autores (2015)

Neste estudo (Tabela 2), pode-se observar que todas as espécies apresentam baixa abundância, com exceção de Licania tomentosa (Benth.) Fritsch (70,88\%), que está acima do limite recomendado pela literatura de 12 a 15\%, pois, segundo Silva et al. (2007), a arborização urbana com alta frequência de uma espécie está susceptível ao ataque de pragas e doenças que podem comprometer a cobertura vegetal da cidade. Portanto, para evitar que isso aconteça, é necessário substituir gradativamente essa espécie por outras, não as plantar mais, ou então, aumentar o número de plantio das demais espécies.

O uso excessivo de Licania tomentosa (Benth.) Fritsch deve ser evitado, pois a alta porcentagem desse exemplar influencia negativamente reduzindo a diversidade de espécies e dificultando a proteção sanitária devido a mesma ser susceptível ao ataque da ferrugem causada por Phakopsora tomentosae; além disso, é considerada de grande porte, característica morfológica não compatível com a largura das calçadas de muitas cidades brasileiras (FERREIRA et al.,2001).

Apesar de apresentar baixa quantidade de exemplares de Thevetia peruviana (Pers.) Schum com apenas cinco indivíduos (Tabela 1) essa espécie é considerada tóxica, pois segundo Batistel et al. (2009) a mesma pode oferecer transtornos à população quando localizada em local 
não adequado, por isso a espécie não é indicada para locais que crianças e animais domésticos frequentam.

No levantamento arbóreo, foram encontradas 16 espécies frutíferas (Tabela 2) comestíveis, que são: Anacardium occidentale L., Mangifera indica L., Spondias mombin L., Annona squamosa L., Carica papaya L., Diospyros kaki L.f., Malpighia glabra L., Artocarpus heterophyllus Lam., Morus nigra L., Psidium guajava L., Syzygium cumini (L) Skeels, Syzygium jambos L.(Alston), Carolus Linnaeus (L.) - Burm.f, Citrus reticulata Blanco, Citrus sinensis (L) osbeck, Talisia esculenta (A. St.-Hil.) Radlk), correspondendo a 118 (6,08\%) exemplares da vegetação, pelos resultados nota-se que essa baixa frequência de indivíduos pode ser explicada provavelmente pela interferência dos cidadãos realizando plantios aleatórios com a finalidade de alimentação humana.

A presença de frutíferas é desejável, pois atrai a fauna local e a aumenta a biodiversidade dentro do ambiente urbano, contudo, deve-se dar preferência àquelas compatíveis com o local de plantio (EMER et al., 2013) e evitar as que possuem frutos médios e grandes, como Mangifera indica L. e Artocarpus heterophyllus Lam., que podem provocar acidentes (PAIVA et al., 2010).

As espécies de menor frequência de ocupação nessa área como: Aspidosperma tomentosum Mart., Mimosa caesalpiniaefolia Benth., Magonia pubescens A.St.-Hil,Jacaranda brasiliana (Lam.), Tecoma stans (L.) Juss. ex Kunth, Handroanthus impetiginosa (Mart. ex DC.) Standl. e Baubinia variegata (L.) Benth devem ser melhor distribuídas nas calçadas da cidade pois apresentam alto potencial para serem utilizadas na arborização de ruas e avenidas por serem classificados de pequeno e médio porte.

\section{Sobre as vias estudadas}

A largura das vias de Gurupi apresentaram variações quanto ao tamanho nas ruas $(6,14-$ $14,97 \mathrm{~m})$, avenidas (12,20-19,90 m) e o canteiro central (1,83 a 3,00 m). Enquanto para as calçadas foi observado uma variação de 1,00 a $15,70 \mathrm{~m}$, conforme mostrado na figura 2 . Dos $66,70 \%$ das calçadas amostradas, apenas $0,76 \%$ apresentou largura inferior a $1,50 \mathrm{~m}$. Conforme regulamento no decreto Lei no 5.296, de 02 de dezembro de 2004, e a NBR 9050/2004 quanto à acessibilidade das pessoas ao espaço livre, o passeio deve ter uma largura de no mínimo $1,50 \mathrm{~m}$ e o mínimo admissível é de 1,20 m, o qual viabiliza a livre circulação, inclusive de pessoas com necessidades especiais (mobilidade reduzida) que utilize cadeira de rodas ou bengalas. Segundo a NBR 9050/2004, além das recomendações de largura de calçadas, outros fatores importantes a 
considerar são os elementos da vegetação como ramos pendentes, plantas entouceiradas, galhos de arbustos e de árvores que não podem interferir na livre circulação dos pedestres.

\section{Figura 2 - Classes de variação de largura de calçadas no setor central de Gurupi (TO).}

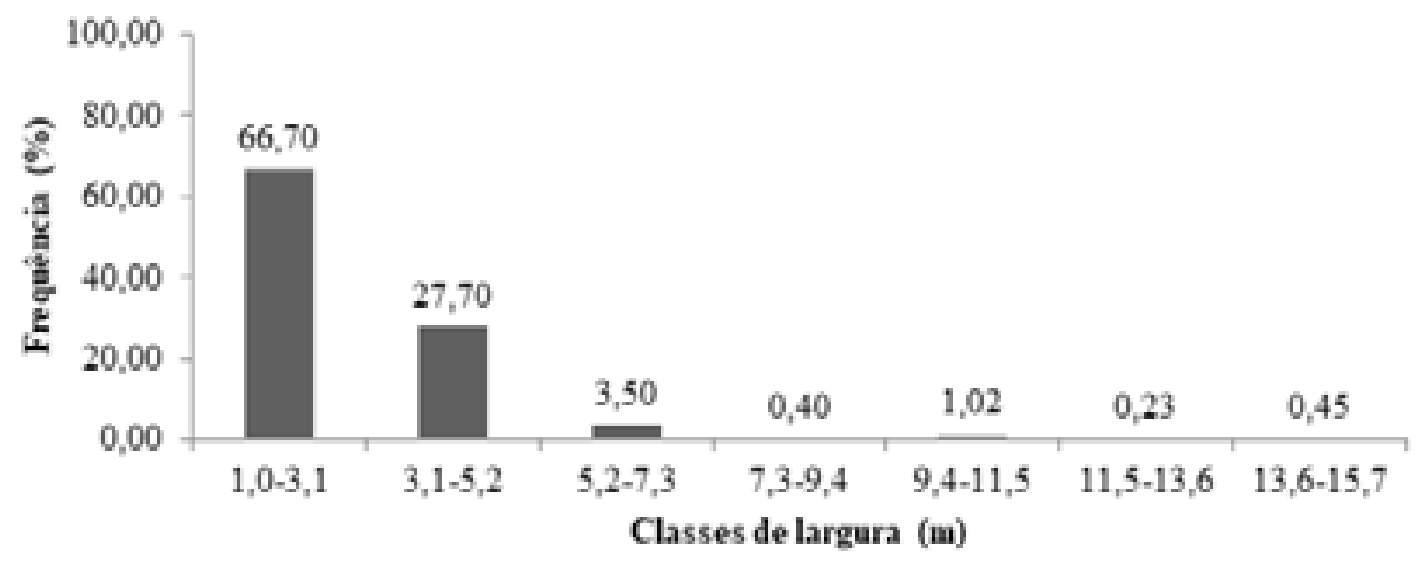

Fonte: Autores (2015).

O planejamento adequado do espaço físico urbano é importante para viabilizar a convivência harmônica entre os elementos construídos, a vegetação introduzida e o acesso livre e seguro para os pedestres. Segundo Miranda e Carvalho (2007), o primeiro passo é delimitar o tamanho das calçadas para indicar o porte das árvores a serem colocadas nas vias públicas, cujos autores indicam árvores com $6 \mathrm{~m}$ de altura para calçadas com largura de $3 \mathrm{~m}$. Segundo as recomendações de Porto e Silva (2013), em função da largura do passeio público, a espécie a ser escolhida deve ser: 1 - somente de pequeno porte, para passeios com largura superior a 1,50 $\mathrm{m}$ e inferior a 2,60 $\mathrm{m}$; 2- de pequeno, médio ou grande porte, para passeios com largura igual ou superior a 2,60 m e inferior a 3,60 m; e 3- de médio ou grande porte, para passeios com largura igual ou superior a 3,60 m (PORTO; SILVA, 2013).

Ainda, segundo Porto e Silva (2013), além de escolher as espécies que melhor se adequem ao espaço disponível, principalmente, quando se pretender implantar árvores em passeios públicos, também é importante levar em conta as características: crescimento inicial rápido; tolerância a pragas e doenças; possuir folhas persistentes ou semicaducas, pequenas e membranáceas; frutos pequenos e apreciáveis pela avifauna; sistema radicular pivotante; floração vistosa; não atrair insetos prejudiciais ao homem; aceitar, porém não exigir, podas frequentes e não possuir espinhos ou produzir substâncias tóxicas.

A altura das árvores variou de 1,50 a 27,19 m (Figura 3), observando-se que a maioria pertence à classe de pequeno porte $(70,4 \%)$, ou seja, altura variando de $1,50 \mathrm{a} 6 \mathrm{~m}$, e médio porte $(26,3 \%)$ representado por indivíduos com altura entre 6 e $12 \mathrm{~m}$. Contudo, uma baixa porcentagem de espécies está inserida na classe de grande porte, isso se deve as podas frequentes (Tabela 3) realizadas nessas plantas para se adequar as estruturas físicas da área urbana como afastamento de construções $(13,3 \%)$, liberação da rede elétrica $(5,3 \%)$, levantamento e abaixamento de copa das árvores $(2,2 \%)$, ou mais de uma forma de manejo no mesmo indivíduo $(6,6 \%)$ tendo em vista que a maioria dos exemplares identificados pertence à classe de grande porte, cuja intensidade de poda variou de leve a drástica contemplando 53,35\% da população. Em decorrência da ausência 
de planejamento da arborização de Gurupi, foram verificados vários casos de podas drásticas, no entanto, para a espécie Pachira aquatica Aubl, foi necessário, uma intervenção mais severa, removendo-a do local porque ela havia destruído a estrutura da calçada e estava colocando em risco a parede da residência (observação pessoal).

\section{Figura 3- Frequência dos indivíduos por classes de altura.}

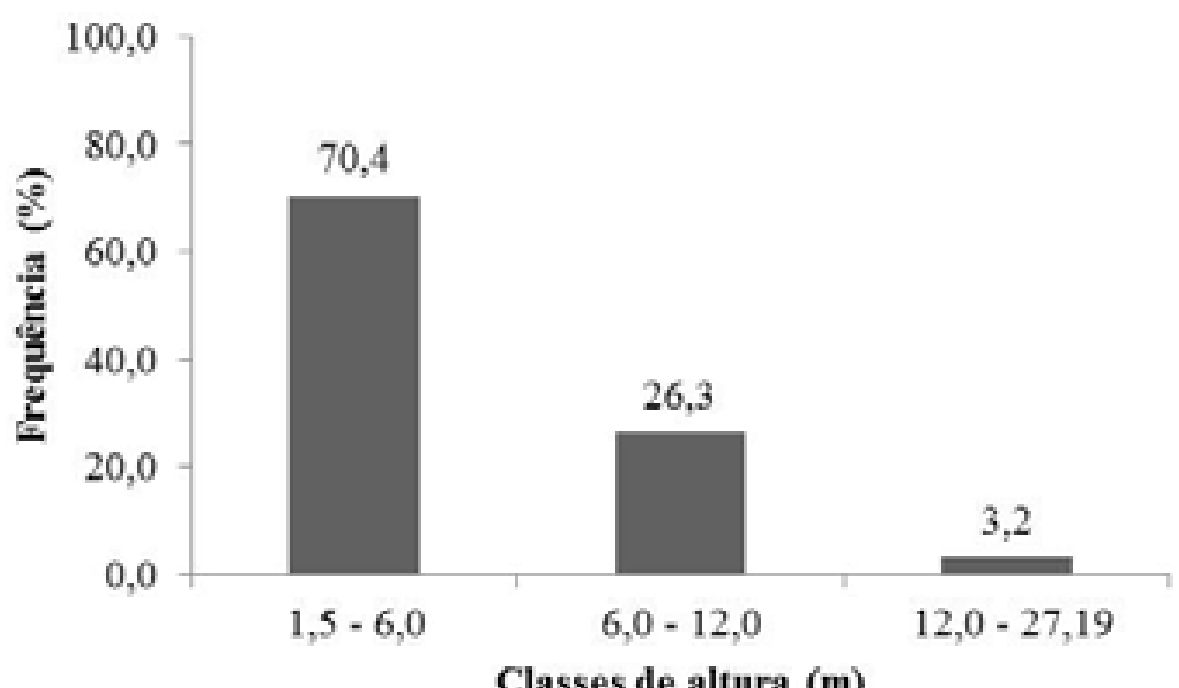

Fonte: Autores (2015).

Em relação à altura da primeira bifurcação, nota-se que 87,6\% dos indivíduos apresentaram valores inferiores a 1,80 m (Tabela 3), constatando que as mudas, antes de serem plantadas na área urbana, foram mal conduzidas, devido estarem abaixo do que é recomendado por Porto e Silva (2013), ou simplesmente o plantio foi realizado por pessoas comuns que não possuem conhecimento técnico sobre a qualidade de mudas. Além disso, alguns exemplares arbóreos adultos dificultavam a passagem e o deslocamento dos pedestres nas calçadas como consequência da má condução dos galhos das plantas no viveiro e também na rua, sendo necessário realizar podas para afastamento de construções em 13,3\% dos indivíduos (Tabela 3). Ainda em relação à necessidade de podas, notou-se que 5,0\% dos indivíduos estão num estágio de desenvolvimento que ainda é importante realizar poda de condução, enquanto para os outros exemplares, é impossível fazer esse manejo, pois o fuste já bifurcou e caso essa poda fosse realizada comprometeria o equilíbrio $\mathrm{da}$ árvore. 


\section{Tabela 3- Frequência dos indivíduos em relação à altura da primeira bifurcação, diâmetro a altura do peito-DAP, intensidade poda e necessidade de poda.}

\begin{tabular}{|c|c|c|c|}
\hline $\begin{array}{c}\text { Altura da primeira } \\
\text { bifurcação }\end{array}$ & $\%$ & DAP & $\%$ \\
\hline$<1,80$ & 87,6 & $<1,30$ & 73,7 \\
\hline$>1,80$ & 12,4 & $>1,30$ & 26,3 \\
\hline Intensidade de poda & $\%$ & $\begin{array}{c}\begin{array}{c}\text { Necessidade de } \\
\text { poda }\end{array} \\
\end{array}$ & $\%$ \\
\hline Nenhuma & 46,7 & Nenhuma & 67,7 \\
\hline Leve & 48,5 & $\begin{array}{l}\text { Afastamento de } \\
\text { construção }\end{array}$ & 13,3 \\
\hline Pesada & 4,1 & $\begin{array}{l}\text { Liberação de } \\
\text { rede elétrica }\end{array}$ & 5,3 \\
\hline \multirow[t]{4}{*}{ Drástica } & 0,7 & $\begin{array}{l}\text { Levantamento de } \\
\text { copa }\end{array}$ & 1,1 \\
\hline & & Condução & 5,0 \\
\hline & & Abaixar copa & 1,1 \\
\hline & & Mais de um & 6,4 \\
\hline
\end{tabular}

Fonte: Autores (2015).

A porcentagem de indivíduos com primeira bifurcação (Tabela 3) acima de 1,80 $\mathrm{m}$ foi de apenas 12,4\% no levantamento arbóreo de Gurupi (TO). Resultados similares a esse (17,60\%) foram observados em Campina Grande (PB) por Araújo et al. (2009) cujos autores alegam que esse fato ocorre devido ao desconhecimento por parte dos órgãos públicos quanto a necessidade de poda de formação em árvores como Ficus benjamina L. para retirar os inúmeros galhos baixos que comprometem o trânsito dos pedestres.

Num bairro de Pato Branco (PR), 53\% dos indivíduos presentes também apresentavam bifurcação menor que $1,80 \mathrm{~m}$, cujo valor é considerado inadequado para a arborização de vias públicas (EMER et al., 2013), tendo em vista que uma muda bem conduzida deve apresentar altura da primeira bifurcação igual a 1,80 m (PORTO; SILVA, 2013). Portanto, para se obterem mudas de qualidade para o plantio na área urbana é necessário selecionar aquelas que possuem fuste reto e também realizar podas de condução para atingir a altura mínima recomendada, sendo essas medidas de grande importância para assegurar o estabelecimento das mesmas e consequentemente evitar riscos de acidentes com as pessoas que transitam nas calçadas (SILVA et al., 2007).

Em relação ao diâmetro à altura do peito (DAP) apenas 26,29\% (Tabela 3) dos indivíduos avaliados apresentaram valores superiores a $1,30 \mathrm{~m}$, essa pequena porcentagem sugere que apenas esses exemplares foram submetidos a podas de condução para atingir uma altura adequada quando estiverem na fase adulta de forma que não gerem conflitos durante o acesso das pessoas nas calçadas. Com esses resultados fica difícil inferir sobre o estágio de desenvolvimento das plantas de maneira geral, já que algumas foram mal conduzidas como Ficus benjamina L. (Figura 
4A) cuja planta apresentava muitas pernadas constatadas pela altura da circunferência do tronco ser inferior a $1,30 \mathrm{~m}$, isso sugere que não foi realizado um manejo adequado, pois se tal prática tivesse sido realizada, a altura em que iniciaria as primeiras ramificações seria superior a 1,80 m.

\section{Figura 4 - Altura da circunferência do tronco inferior a $1,30 \mathrm{~m}$ em Ficus benjamina L.(A) com a presença de muitas pernadas e área livre insuficiente para o seu crescimento, e área livre totalmente impermeabiliza gerando trincas pelas raízes de Cassia fistula L (B) na calçada.}
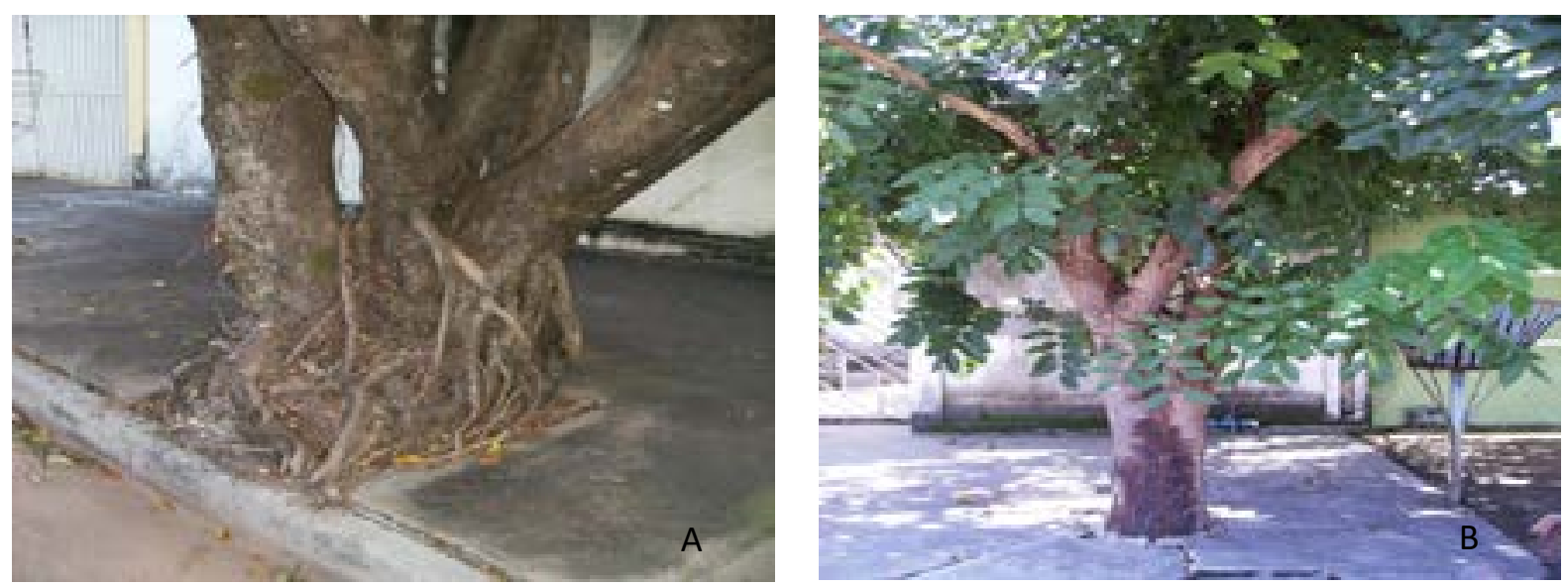

Fonte: Autores (2015).

Podemos observar que $92,3 \%$ dos indivíduos adultos estão localizados em calçadas pavimentadas (Tabela 4), sendo desse total verificado que as raízes de 47,3\% das árvores causavam algum tipo de dano. Tal fato ocorre devido à incompatibilidade do porte das espécies para o espaço disponível ou área livre insuficiente para o seu crescimento, ou seja, o problema na verdade foi a escolha inadequada da espécie para o local onde foi plantada que é insuficiente para o seu desenvolvimento, além disso, muitas vezes as condições para a sobrevivências das mesmas são mínimas, o que é constatado pela exposição das raízes superficiais de Ficus benjamina L. (Figura 4A). Outro caso é o exemplificado pela árvore Cassia fistula L., cuja área livre para o seu desenvolvimento está completamente impermeabilizada e, como consequência disso, é observado trincas nas calçadas provocadas pela pressão exercida por suas raízes (Figura 4B). Além das espécies citadas também podemos constatar que Mangifera indica L., Pachira aquatica Aubl., Syzygium malaccense (L.) Merr. \& L.M. Perry e Caesalpinia pluviosa D.C. foram as maiores responsáveis pelos danos do tipo trinca e quebra das calçadas, confirmando o uso indevido dessas árvores em calçadas estreitas, as quais deveriam estar situadas em praças públicas. 


\section{Tabela 4 - Frequência de indivíduos com ausência ou presença de pavimentação, danos às calçadas por raízes, tipos de injúrias e conflitos das árvores em relação à fiação elétrica.}

\begin{tabular}{|c|c|c|c|c|c|c|c|}
\hline Pavimentação & $\%$ & $\begin{array}{c}\text { Danos às calçadas } \\
\text { por raízes. }\end{array}$ & $\%$ & Injúria & $\%$ & $\begin{array}{l}\text { Fiação } \\
\text { elétrica }\end{array}$ & $\%$ \\
\hline Sim & 92,3 & Ausente & 52,7 & Ausente & 14,6 & Ausente & 64,5 \\
\hline \multirow[t]{4}{*}{ Não } & 7,7 & Aponta/trinca & 34,3 & Poda & 33,7 & Abaixo da copa & 0,6 \\
\hline & & Quebra & 13,0 & Vandalismo & 9,9 & Atravessa a copa & 10,0 \\
\hline & & & & Doença e praga & 0,2 & Acima copa & 25,0 \\
\hline & & & & Mais de um & 41,6 & & \\
\hline
\end{tabular}

Fonte: Autores (2015).

Danos causados às calçadas decorrente da pressão exercida pelas raízes de árvores também foi constantemente encontrados em Remígio (PB), tal fato ocorre porque plantas de grande porte acarretam conflitos na estrutura urbana comprometendo o piso, as estruturas de muros e, além disso, impedem a visibilidade de placas de trânsito (BATISTA et al., 2013) e, também, devido à incompatibilidade do espaço disponível na calçada para o desenvolvimento da árvore, assim como, o uso de covas pequenas e falta de orientação técnica (ALENCAR, 2012).

$\mathrm{Na}$ tentativa de solucionar a ausência de espaço para o bom desenvolvimento das plantas na área urbana, a Secretária do Meio Ambiente e Sustentabilidade (SMAS, 2013) propõem incentivar a construção de calçadas verdes ou ecológicas, cuja finalidade é reduzir a impermeabilização das calçadas através do uso de material permeável como, faixas de gramado em consonância com a arborização da área pavimentada, e Porto e Silva (2013) sugere deixar uma área livre de $1 \mathrm{~m}^{2}$, não pavimentada em torno de cada árvore, independente do formato.

Com relação às injúrias (Tabela 4), observa-se que 41,6\% da vegetação foi acometida por mais de um tipo ao mesmo tempo, sendo verificado que $33,7 \%$ das árvores apresentavam-se mal podadas com danos de poda evidenciados nos galhos decorrentes de cortes mal feitos e $9,9 \%$ com sinais de vandalismo resultante de atos como: pintura do tronco com cal, placas de notificações de advertência e/ou propaganda, pregos fixados e evidências de escritas feitas por estilete, e $0,2 \%$ das plantas com sinais de pragas e doenças.

A presença de injúrias devido a atos de vandalismo, assim como poda mal conduzidas, presença de pragas e doenças é comum na arborização de Gurupi como em outras cidades brasileiras. Emer et al. (2013) complementam que, a grande maioria das injúrias são provocadas pelas intervenções de poda, que consequentemente, acabam potencializando problemas de ordem sanitária como: o ataque de pragas e o surgimento de doenças em função da geração de ferimentos e exposição dos tecidos internos da árvore, além de problemas de ordem estética e funcional acarretando na perda da viabilidade e da vida útil da planta.

A maioria das árvores foram plantas no lado da calçada cuja fiação elétrica é ausente (64,5\%), sendo assim, os demais indivíduos que estavam situados no lado oposto da calçada apresentavam algum tipo de conflito com a fiação devido à ausência de planejamento e/ou incompatibilidade do porte da planta com essa estrutura física da área urbana (Tabela 4). Verificou-se que 25,0\% das árvores ainda não apresentavam conflitos, pois estavam localizadas abaixo da fiação, mas devido a maioria das plantas estarem em desenvolvimento (fase de muda), especialmente, Licania 
tomentosa (Benth.) Fritsch, Pachira aquatica Aubl. e Caesalpinia pluviosa DC., todas apresentaram potencial futuro para conflitar com a rede de energia elétrica o que demandará a realização de podas emergenciais para sanar esse problema ou substituir a fiação comum pela protegida. Alguns exemplares (10\%) são considerados problema atual, tendo em vista que estavam plantados sob a fiação elétrica, cuja copa das árvores era atravessada pelos fios, portanto nesses indivíduos será necessário realizar podas frequentes para adequá-los ao ambiente.

O conflito entre a arborização e a rede elétrica é comum em diversas cidades brasileiras, devido à ausência de planejamento ou de forma desordenada do plantio das árvores, dessa forma, a solução na maioria das vezes é realizar podas mutiladoras, deixando o vegetal desprovido de copa (SILVA et al., 2007). Esses conflitos com a fiação elétrica são consequência do plantio de árvores de grande porte como: Tabebuia alba (Rild.) Sand., Terminalia catappa L. e Delonix regia (Boj. ex Hook.) Raf. (FARIAS et al., 2007). Em Goiandira a situação da arborização é ainda mais grave devido à ausência do planejamento, onde são observados constantes plantios de forma aleatória pela própria população. E como consequências dessa prática são observadas excessivas quantidades de podas pesadas mutiladoras, cuja principal finalidade é eliminar a interferência das plantas na rede elétrica, no entanto, essas ações corretivas geram problemas como o comprometimento da vida útil e a função estética das árvores (PIRES et al., 2010), dessa forma, uma maneira de evitar o confronto das árvores com a fiação seria a plantação de espécies de pequeno a médio porte.

De acordo com as informações levantadas neste estudo pode-se constatar que para haver a melhoria da arborização de Gurupi é necessário colocar árvores de porte compatível com as estruturas físicas da mesma, de forma que não comprometa a livre circulação das pessoas nas calçadas e tenha espaço suficiente para o vegetal se desenvolver sem acarretar danos nas calçadas. O espaço de área livre destinado ao desenvolvimento das plantas deve ser de pelo menos $1 \mathrm{~m}^{2}$ ou superior dependendo da largura das calçadas para evitar a quebra das mesmas. Nas residências que ainda não possuam árvores de acompanhamento viário, o ideal é que se dê preferência ao uso de calçadas verdes, pois além de ser ecologicamente correto, apresenta maior espaço para que as árvores possam se desenvolver, fixar, evitar o tombamento na época dos ventos fortes e chuvas e ainda serve como área de recreação para as crianças.

A escolha correta das espécies de árvores a serem implantadas na cidade evita os custos onerosos da prefeitura com podas, reduziria a presença de injúrias e ferimento nas plantas decorrentes de podas malfeitas e outra medida que poderia ser implantada seria a substituição da fiação elétrica comum pela protegida.

\section{Conclusão}

Conforme dados e discussão dos resultados pode-se concluir que:

Os principais problemas apresentados são: a baixa diversidade de espécies, onde predomina Licania tomentosa (Benth.) Fritsch; uso de espécies de grande porte incompatíveis com o espaço disponível, como Pachira aquatica Aubl, Mangifera indica L., Syzygium malaccense (L.) Merr. \& L.M.Perry e Caesalpinia pluviosa D.C. que foram responsáveis pelos danos às calçadas e também pode entrar em conflito com a fiação elétrica.

Os indivíduos adultos em sua maioria (92,3\%) estão localizados em calçadas pavimentadas, sendo deste total verificado que as raízes de $47,3 \%$ das árvores causavam algum tipo de dano. 
O uso de mudas de plantas mal conduzidas é um problema gravíssimo constatado pela altura da primeira bifurcação, bem como através do diâmetro à altura do peito nas árvores adultas, o que reflete diretamente nos custos de manutenção com podas.

As árvores de grande porte devem ser destinadas às praças da cidade que apresenta maior espaço para o seu desenvolvimento e o crescimento.

\section{Referências}

ALENCAR, L.S. Inventário quali-quantitativo da arborização urbana em São João do Rio do Peixe-PB, 2012. 41f. Monografia (Graduação em Engenharia Florestal). Universidade Federal de Campina Grande, Patos, 2012.

APG III. An update of the Angiosperm Phylogeny Group classification for the orders and families of flowering plants: APG III. Botanical Journal of the Linnean Society, v.161, n.2, p.105-121, 2009. DOI: 10.1111/j.1095-8339.2009.00996.x

ARAÚJO, A.C.; RIBEIRO, I.A.M.; MORAIS, M.S.; ARAÚJO, J.L.O. Análise qualiquantitativa da arborização no bairro presidente Médici, Campina Grande-PB. Revista da Sociedade Brasileira de Arborização Urbana, Piracicaba - SP, v.4, n.1, p.133-144, 2009. Disponível em: http://www.revsbau.esalq.usp.br/artigos_cientificos/artigo66versao_publicacao.pdf. Acesso: 13 abri. 2014.

BATISTA, F.A.; CHAVES, T.P.; FELISMINO, D.C.; DANTAS, I.C. Inventário quali-quantitativo da arborização urbana na cidade de Remígio, Paraíba. Revista de Biologia e Farmácia, Campina Grande/PB, v.9, n.1, p.1-6, 2013. Disponível em: http://sites.uepb.edu.br/biofar/download/v9n1-2013/ecologia_e_meio_ ambiente/INVENT\%C3\%81RIO\%20QUALI-QUANTITATIVO\%20DA\%20 ARBORIZA\%C3\%87\%C3\%83O\%20URBANA\%20NA\%20CIDADE\%20DE\%20 REM\%C3\%8DGIO,\%20PARA\%C3\%8DBA.pdf. Acesso: 12 abri. 2014.

BATISTEL, L.M.; DIAS, M.A.B.; MARTINS, A.S.; RESENDE, I.L.M. Diagnóstico qualitativo e quantitativo da arborização urbana nos bairros Promissão e Pedro Cardoso, Quirinópolis, Goiás. Revista da Sociedade Brasileira de Arborização Urbana, PiracicabaSP, v.4, n.3, p.110-129, 2009. Disponível em: http://www.revsbau.esalq.usp.br/artigos_ cientificos/artigo89.pdf. Acesso: 12 abri. 2014.

CARVALHO, P.E.R. Espécies arbóreas brasileiras. Brasília: Embrapa Informação Tecnológica, 2003, v. 1, 1039p.

CARVALHO, P.E.R. Espécies arbóreas brasileiras. Ed. Brasília: Embrapa Informação Tecnológica, 2006, v.2, 627p.

CARVALHO, P.E.R. Espécies arbóreas brasileiras. Ed. Brasília: Embrapa Informação Tecnológica, 2008, v. 3, 593p. 
CORREIA, M.P. Dicionário das plantas úteis do Brasil e das exóticas cultivadas. (6v.) Rio de Janeiro: IBDF, 1984.777p.

DANTAS, I.C.; SOUZA, C.M.C. Arborização urbana na cidade de Campina Grande - PB: Inventário e suas espécies. Revista de Biologia e Ciências da Terra, Campina grande, v.4, n.2, p.1-8, 2004. Disponível em: http://eduep.uepb.edu.br/rbct/sumarios/ pdf/arborizaurbana.pdf. Acesso em: 12 abri. 2014.

EMER, A.A.; SILVA, L.; CADORIN, D.A.; MELLO, N.A. Avaliação quantitativa e qualitativa da arborização do bairro Santa Terezinha na cidade de Pato Branco (PR). Ambiência, Guarapuava-PR, v.9, n.1, p.129-143, 2013. DOI:10.5777/ ambiencia.2013.01.09.

FARIA, J.L.G; MONTEIRO, E.A.; FISCH, S.T.V. Arborização de vias públicas do município de Jacareí-SP. Revista Brasileira de Arborização Urbana, Piracicaba-SP, v.2, n.4, p.20-33, 2007. Disponível em: http://www.revsbau.esalq.usp.br/artigos_cientificos/ artigo29.pdf. Acesso em: 12 abri. 2014.

FERREIRA, F.A.; GASPAROTTO, L.; LIMA, M.I P M. Uma ferrugem, causada por Phakopsora tomentosae sp. em oiti, em Manaus. Fitopatologia Brasileira, Brasília, v.26, n.2, p. 206-208, 2001.

Disponível em: http://www.scielo.br/pdf/fb/v26n2/a16v26n2.pdf. Acesso em: 12 abri. 2014.

IBGE 2018. Informações estatísticas. (Instituto Brasileiro de Geografia e Estatística). Acesso em: $<$ http://cidades.ibge.gov.br/xtras/perfil.php?lang=\&codmun=170950\&search = linfogr\%E1ficos:-informa\%E7\%F5es-completas. Disponível em: 15-03-2018.

LORENZI,H. Árvores brasileiras: manual de identificação de plantas arbóreas nativas do Brasil. 2ed. Nova Odessa, SP: editora Plantarum, 1998a. 352p.

LORENZI, H. Árvores brasileiras: manual de identificação de plantas arbóreas nativas do Brasil. 2ed. Nova Odessa, SP: editora Plantarum, 1998b. 352p.

LORENZI, H. Árvores Exóticas do Brasil: madeireiras, ornamentais e aromáticas, 1 ed. Nova Nova Odessa: Instituto Plantarum, 2003, 384p.

MELO, R.R.; LIRA FILHO, J.A.; RODOLFO JÚNIOR, F. Diagnóstico qualitativo e quantitativo da arborização urbana no bairro Bivar Olinto, Patos, Paraíba. Revista da Sociedade Brasileira de Arborização Urbana, Piracicaba - SP, v.2, n.1, p.64-80, 2007. Disponível em: http://www.revsbau.esalq.usp.br/artigos_cientificos/artigo13.pdf. Acesso em: 12 abri. 2014.

MIRANDA, T.O.; CARVALHO, S.M. Levantamento quantitativo e qualitativo de 
indivíduos arbóreos presentes nas vias do bairro da Ronda em Ponta Grossa-PR. Revista Brasileira de Arborização Urbana, Piracicaba-SP, v.4, n.3, p. 143-157, 2009. Disponível em: http://www.revsbau.esalq.usp.br/artigos_cientificos/artigo95.pdf. Acesso em: 12 abri. 2014.

MONTEIRO, M.M.G.; TETTO, A.F.; BIONDI, D.; SOUZA, R.R. Percepção dos usuários em relação à arborização da avenida Cândido de Abreu-Curitiba-PR. Revista da Sociedade Brasileira de Arborização Urbana, Piracicaba-SP, v.8, n.2, p20-34, 2013. Disponível em: http://www.revsbau.esalq.usp.br/artigos_cientificos/artigo50snpublicacao.pdf. Acesso em: 12 abri. 2014.

OSAKO, L.K.; TAKENAKA, E.M.M.; SILVA, P.A.; Arborização urbana e a importância do planejamento ambiental através de políticas públicas. Revista cientifica, v.9, n.14, p.1-8, 2016. Disponível em: http://www.amigosdanatureza.org.br/publicacoes/index.php/ anap_brasil/article/view/1318/1340. Acesso em: 07 set. 2018.

PAIVA, V. A.; LIMA, A.B.M.; CARVALHO, A.; M. JUNIOR, A.; GOMES, A.; MELO, C.S.; FARIAS, C.O.; REIS, C.; BEZERRA, C.; S.JUNIOR, E.A.S.; MACEDO, E.; LIMA, E.S.; SOBRINHO, F.; SILVA, F.M.; BONFIM, J.C.; JUNIOR, L.S.; CORREA, M.; DUMONT, M.L.; ISAAC JUNIOR, M.A; PANTOJA, N.V.; DAVILA, R.M.; GABRIEL, R.; SILVA, R.A.; CUNHA, R.M.; OLIVEIRA, R.S.; DIAS, R.; NICHELI, S.P.; COSTA, S.; SOUZA, T.C.; PEREIRA, T.F.; CASTELO, Z.; FERRARI, Z.S. Inventário e diagnóstico da arborização urbana viária de Rio Branco, AC. Revista da Sociedade Brasileira de Arborização Urbana, Piracicaba-SP, v.5, n.1, p.144-159, 2010. Disponível em: http://www.revsbau.esalq.usp.br/artigos_cientificos/artigo86-publicacao.pdf. Acesso em: 12 abri. 2014.

PIRES, N.A.M.; MELO, M.S.; OLIVEIRA, D.E.; XAVIER-SANTOS, S. A arborização urbana do município de Goiandira/GO - caracterização quali-quantitativa e propostas de manejo. Revista Brasileira de Arborização Urbana, Piracicaba-SP, v.5, n.3, p.185-205, 2010. Disponível em: http://www.revsbau.esalq.usp.br/artigos_cientificos/artigo132publicacao.pdf. Acesso em: 12 abri. 2014.

PORTO, L.P.M.; SILVA, H.M.; Manual de Orientação Técnica da Arborização Urbana de Belém. Manual de Orientação Técnica da Arborização Urbana de Belém: guia para planejamento, implantação e manutenção da arborização em logradouros públicos. Belém: Universidade Federal Rural da Amazônia, 2013. 108p. Disponível em: http://ww3. belem.pa.gov.br/www/wp-content/uploads/Manual-de-Arboriza\%C3\%A7\%C3\%A3ode-Bel\%C3\%A9m.pdf. Acesso em: 17 jul. 2014.

RABER, A.P.; RABELATO, G.S. Arborização viária do município de Colorado, RS Brasil: análise quali-quantitativa. Revista da Sociedade Brasileira de Arborização Urbana, Piracicaba-SP, v.5, n.1, p.183-199, 2010. Disponível em: http://www.revsbau. 
esalq.usp.br/artigos_cientificos/artigo114-publicacao.pdf. Acesso em: 17 jul. 2014.

SANTOS, A.F.; JOSÉ, A.C.; SOUSA, P.A. Fitossociologia e diversidade de espécies arbóreas das praças centrais do município de Gurupi - TO. Revista da Sociedade Brasileira de Arborização Urbana, Piracicaba - SP, v.8, n.4, p.36-46, 2013. Disponível em: http://www.revsbau.esalq.usp.br/artigos_cientificos/artigo 71sn-publicacao.pdf. Acesso em: 17 jul. 2014.

Secretaria de Meio Ambiente e Sustentabilidade (SMAS). Prefeitura da Cidade do Recife. Manual de arborização: orientações e procedimentos técnicos básicos para a implantação e manutenção da arborização da cidade do Recife. 1. Ed, Recife: [s.n.], 2013. 71 p. Disponível em: http://www2.recife.pe.gov.br/wp-content/uploads/Manual_Arborizacao. pdf. Acesso em: 17 jul. 2014.

Secretaria do Planejamento e da Modernização da Gestão Pública- SEPLAN. Atlas do Tocantins: subsídios ao planejamento da gestão territorial. Acesso em: http://www. seplan.to.gov.br/Portal/acontece/atlas2012. Disponível em: 03 jul. 2014.

Secretaria do Planejamento e da Modernização da Gestão Pública- SEPLAN. GURUPISeplan - Governo do Estado do Tocantins. http://www.seplan.to.gov.br/Arquivos/ download/Municipios Perfil 2013/Gurupi.pdf. Disponível em: 03 jul. 2014.

SILVA, A.G.; PAIVA, H.N.; GONÇALVES, W.Avaliando a arborização urbana.1.ed. Viçosa, MG: Aprenda Fácil, 2007.346p

SILVA, A.G; CARDOSO, A.L.; RAPHAEL, M. Diagnóstico quali-quantitativo da arborização viária da cidade de Jerônimo Monteiro, ES. Enciclopédia Biosfera, Centro Científico Conhecer - Goiânia-GO, v.8, n.14; p.1179-1188, 2012. Disponível em: http:// www.conhecer.org.br/enciclop/2012a/ambientais/diagnostico\%20quali\%20quantitativo. pdf. Acesso em: 17 jul. 2014.

VIBRANS, A.C.; GASPER, A.L.; MÜLLER, J.J.V. Para que inventariar florestas? reflexões sobre a finalidade do inventário florístico florestal de Santa Catarina. Revista de Estudos Ambientais (Online), v.14, n.1esp, p. 6-13, 2012. Disponível em: http://gorila. furb.br/ojs/index.php/rea/article/viewFile/2851/1956. Acesso em: 07 set. 2018. 